\title{
Power Split Supercharging: A Mild Hybrid Approach to Boost Fuel Economy ${ }^{\dagger}$
}

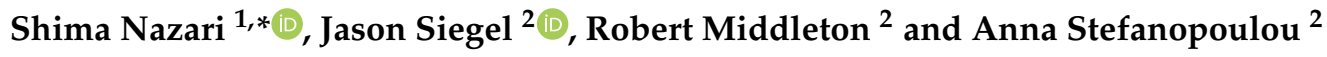 \\ 1 Department of Mechanical Engineering, Universiy of California Davis, Davis, CA 95616, USA \\ 2 Department of Mechanical Engineering, University of Michigan, Ann Arbor, MI 48109, USA; \\ siegeljb@umich.edu (J.S.); rjmidd@umich.edu (R.M.); annastef@umich.edu (A.S.) \\ * Correspondence: snazari@ucdavis.edu; Tel.: +1-530-752-5801 \\ + This paper is an extended version of our paper published in 2019 WCX World Congress Experience, \\ Detroit, MI, USA, 9-11 April 2019; No. 2019-01-1207.
}

Received: 17 November 2020; Accepted: 9 December 2020; Published: 14 December 2020

\begin{abstract}
This work investigates an innovative low-voltage $(<60 \mathrm{~V})$ hybrid device that enables engine boosting and downsizing in addition to mild hybrid functionalities such as regenerative braking, start-stop, and torque assist. A planetary gear set and a brake permit the power split supercharger (PSS) to share a $9 \mathrm{~kW}$ motor between supercharging the engine and direct torque supply to the crankshaft. In contrast, most e-boosting schemes use two separate motors for these two functionalities. This single motor structure restricts the PSS operation to only one of the supercharging or parallel hybrid modes; therefore, an optimized decision making strategy is necessary to select both the device mode and its power split ratio. An adaptive equivalent consumption minimization strategy (A-ECMS), which uses the battery state of charge (SoC) history to adjust the equivalence factor, is developed for energy management of the PSS. The A-ECMS effectiveness is compared against a dynamic programming (DP) solution with full drive cycle preview through hardware-in-the-loop experiments on an engine dynamometer testbed. The experiments show that the PSS with A-ECMS reduces vehicle fuel consumption by $18.4 \%$ over standard FTP75 cycle, compared to a baseline turbocharged engine, while global optimal DP solution decreases the fuel consumption by $22.8 \%$ compared to the baseline.
\end{abstract}

Keywords: energy management; hybrid electric vehicle; powertrain electrification; equivalent consumption minimization; supercharging; hardware-in-the-loop experiments

\section{Introduction}

Hybrid electric vehicles (HEVs) are one of the promising solutions for reducing carbon emissions in the transportation sector. During the past two decades, many different architectures for hybridized powertrains have emerged [1]. Unfortunately, despite their relative technology maturity and their proven effectiveness in reducing fuel consumption, the market penetration of HEVs is still poor [2]. The main factor for low sales rates is the higher initial cost of these vehicles compared to traditional vehicles with only internal combustion engines (ICEs). In contrast to expensive full HEVs, which use high-voltage/-power electric machines and electronics, this work investigates an economical low-voltage hybrid system, called a power split supercharger (PSS), as shown in Figure 1.

The PSS, configured with a $9 \mathrm{~kW} 48 \mathrm{~V}$ motor, can drive a supercharger to pressurize the intake air of the engine or it can operate as a regular parallel hybrid system and supply/draw torque directly to/from the crankshaft when the supercharger is locked and bypassed. The inadequate torque of a small naturally aspirated (NA) ICE requires conventional mild hybrid systems to employ larger NA or boosted ICEs for full performance. However, the PSS can provide sufficient boost to a small 
engine to provide good acceleration while taking advantage of engine downsizing and hybridization to improve efficiency.

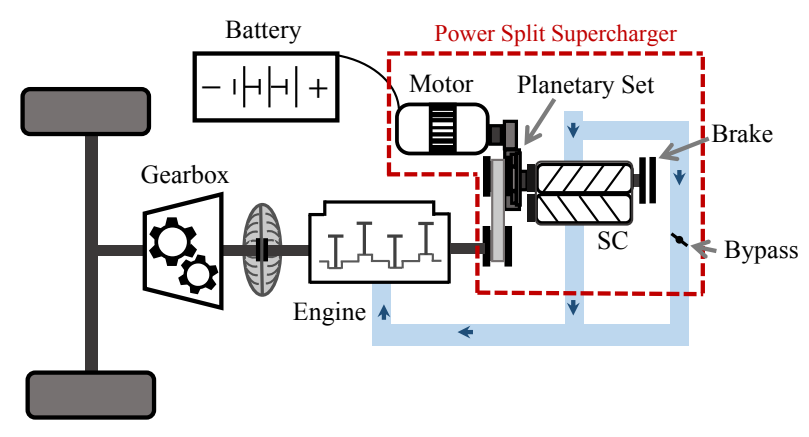

Figure 1. Powertrain schematic with a power split supercharger.

The planetary gear set and the electric motor speed control capability decouple the boost pressure generated by the PSS from the crankshaft speed, resulting in a fast torque response and improved vehicle drive-ability compared to traditional boosting devices, such as turbochargers or mechanical superchargers. Flexible supercharging can also be achieved with an electric supercharger such as the HyBoost system from Valeo [3]. However, powering the supercharger solely with electricity necessitates a larger battery and motor, leading to a higher system cost. Figure 2a shows the required supercharger mechanical power in a $1.6 \mathrm{~L}$ gasoline engine studied here, while Figure $2 \mathrm{~b}$ shows the corresponding motor power in the PSS system for different engine speeds and torques. While for the range of operating points shown the supercharger power is as high as $15 \mathrm{~kW}$, most of this power is supplied by the engine crankshaft. In every operating condition either a small portion of the power comes from the motor or the motor is slightly generating. This characteristic is especially useful for scenarios such as hill climbing, shown in Figure 3, where the supercharger has to provide a continuous boost pressure due to the high requested torque. For the simulated example shown in Figure 3, vehicle cruising at $110 \mathrm{~km} / \mathrm{h}$ with a road grade of $5^{\circ}$ for $20 \mathrm{~min}$, a small SUV with the PSS would slightly charge a $2.5 \mathrm{~kW} . \mathrm{h}$ battery, while a purely electric supercharger (eSC) would completely deplete the battery, as demonstrated in Figure $3 b$. The modeled vehicle and engine are explained in further detail in the following sections.

This electric power and energy accessibility problem has pushed vehicle manufacturers to use electric superchargers in combination with a turbocharger, examples of which are Volvo T6 and T8 engines [4]. In these powertrains, the turbocharger can be used during steady state, and the supercharger can make the transients faster. The PSS system, however, can be used as a stand-alone boosting device reducing the system cost in addition to enabling hybrid functionalities such as regenerative braking and start-stop. This work develops an online energy management system for an engine equipped with a PSS and experimentally verifies the fuel economy benefits of the device when it replaces a conventional turbocharger.

While in traditional vehicles the driver's entire requested torque is supplied by an ICE, HEVs need an effective energy management system to determine the power split ratio between the engine and the battery at each time instant. Energy management methods for HEVs are extensively investigated in literature. These methods are often classified as optimization-based methods and rule-based methods [5,6]. Rule-based approaches are usually a set of conditional statements based on simple principles and heuristics; hence, they are easily implementable. As an example, thermostatic control, which is developed for a series HEV [7], turns the engine on or off depending on the battery SoC. Although some rules are derived from optimization results, these methods do not fully exploit the powertrain flexibility and do not guarantee optimal performance. Furthermore, the generated rules are not reusable for a different powertrain configuration or control objective. 


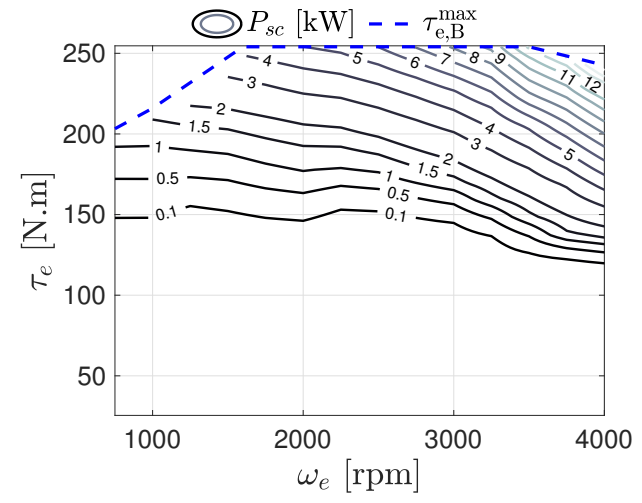

(a) supercharger.

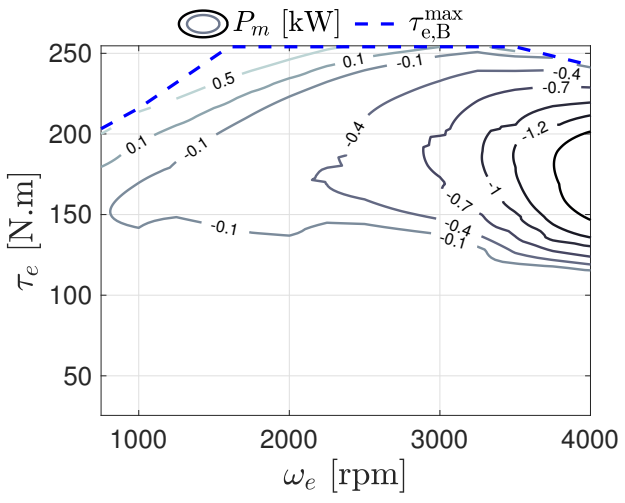

(b) motor.

Figure 2. (a) Supercharger mechanical power, (b) corresponding motor power in the power split supercharger (PSS) system, both for a 1.6 L gasoline engine.

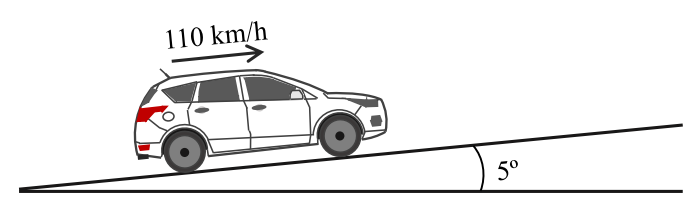

(a)

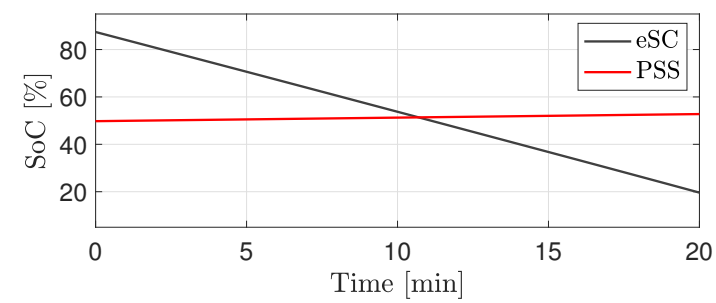

(b)

Figure 3. (a) Vehicle climbing a $5^{\circ}$ hill at $110 \mathrm{~km} / \mathrm{h}$, (b) a $2.5 \mathrm{kWh}$ battery state of charge (SoC) variation for the vehicle with PSS compared to the same vehicle with an electric supercharger (eSC).

Optimization-based approaches can more effectively identify optimum solutions at the price of complexity as they minimize a cost function subject to the system physics and constraints. Various performance metrics such as fuel consumption or emissions can be included in the optimization cost function to achieve different performance goals. The optimization horizon can vary from a single time step, as in equivalent consumption minimization strategy (ECMS) [8], to multiple time steps, such as with model predictive control (MPC) [9], or over the entire drive cycle, as in dynamic programming (DP) $[10,11]$. Note that only the methods that minimize fuel consumption over the full drive cycle give the global optimum solution; however, these methods are prohibitively computationally expensive while also requiring knowledge of future driver demands. Nevertheless, they provide a criterion for evaluating other energy management algorithms in addition to giving insight into optimal policies.

The charge-sustaining global optimal energy management strategy for a vehicle with the PSS was formulated and solved using DP in a prior work [12], and a simple online energy management system based on ECMS was also previously presented and tested in simulation [13]. This work extends our previous efforts by developing an Adaptive-ECMS (A-ECMS) and documenting the fuel economy benefits of the PSS through advanced hardware-in-the-loop (HIL) experiments. The main contributions of this work are as follows: first, an Adaptive-ECMS energy management system is introduced to select the PSS mode and its power split ratio. Second, the implementation of the hardware-in-the-loop experiments is described in detail, and some practical challenges are explained. Third, the operation of the PSS is demonstrated experimentally, and finally, the effectiveness of the PSS hardware and the developed controllers in fuel consumption reduction of a vehicle is quantified over the standard FTP75 cycle.

After introducing the utilized hardware and models, the global fuel consumption minimization problem is described briefly. An ECMS is formulated for selecting the PSS mode and its power 
split ratio in Section 3.2 and the Adaptive-ECMS is described in Section 3.3. Section 4 presents the engine dynamometer experimental testbed and the details of HIL implementation. The experimental demonstration of fuel economy results and PSS operation are shown in Section 5, and the paper concludes with the main findings of the work.

\section{Experimental Hardware and Model Framework}

The baseline engine is a $1.6 \mathrm{~L}$ Ford EcoBoost engine, which is a 4 cylinder spark ignition (SI) turbocharged engine. The turbocharger is replaced by the PSS in the alternative powertrain studied in this work. Figure 1 shows a schematic view of the engine with the PSS and other powertrain components. The PSS is configured with a planetary gear set, a roots supercharger, a motor, a bypass valve, and a brake. The sun gear is attached to the supercharger, the ring is connected to the motor, and the carrier is coupled with the engine crankshaft through a set of belt and pulleys. The PSS can enable two distinct operating modes by controlling the motor, bypass, and the brake. In boosting mode, the bypass is closed, the brake is released, and the motor can control the supercharger speed and resulting boost pressure independently of the crankshaft speed. In torque assist mode, the brake locks the sun gear and the supercharger is bypassed. In this mode the planetary gear set acts as a regular gear set, which enables the motor to supply/draw torque to the crankshaft for start-stop, regenerative braking, or assisting the crankshaft. The engine fuel consumption map, shown in Figure 4, is produced using a high-fidelity GT-Power model, which is described in detail and validated against engine dynamometer experiments elsewhere [14]. In Figure $4, \tau_{e, N A}^{\max }$ is the maximum torque that the NA engine can produce, $\tau_{e, B}^{\max }$ is the maximum engine torque when the PSS is in boosting mode, and $\left(\tau_{e, N A}+\tau_{\mathrm{TA}}\right)^{\text {max }}$ is the powertrain maximum torque in torque assist mode (maximum motor torque added to the crankshaft).

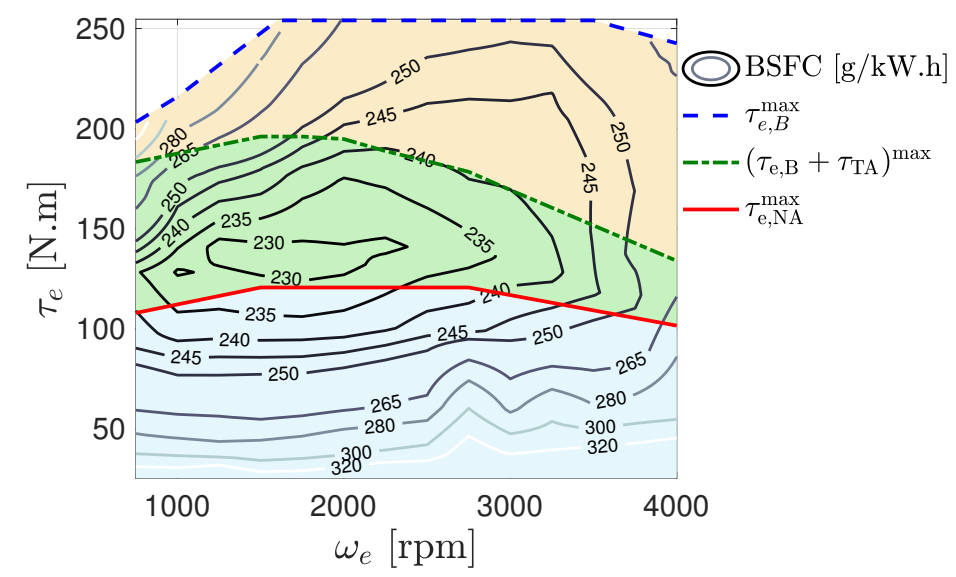

Figure 4. Brake specific fuel consumption (BSFC) map for the engine with the power split supercharger (PSS). The naturally aspirated engine maximum torque, $\tau_{e, \mathrm{NA}}^{\max }$, the powertrain maximum torque in torque assist mode, $\left(\tau_{e, \mathrm{NA}}+\tau_{\mathrm{TA}}\right)^{\max }$, and the maximum engine torque during boosting mode, $\tau_{e, \mathrm{~B}}^{\max }$, are also represented.

The modeled vehicle is a MY2015 Ford Escape crossover SUV. The drivetrain model includes the crankshaft dynamics, a friction clutch, a torque converter, and a 6-speed automatic transmission. The model details and control strategy are described in a prior work [14]. The driver model is a gain-scheduled proportional + integral (PI) controller and uses a $1 \mathrm{~s}$ preview of the tracking error and vehicle acceleration. A $1.2 \mathrm{kWh}$ lithium-ion battery is assumed for the rest of this study. An open circuit voltage with a resistance (OCV-R) is used to model the battery and compute its state of charge dynamics, detailed in [12]. 


\section{Energy Management System}

\subsection{Global Fuel Consumption Minimization}

The optimal energy management problem for a vehicle with a PSS and with the full driving profile preview was formulated and solved using DP elsewhere $[12,15]$. In this work the DP solution was used as a benchmark to evaluate the effectiveness of the online energy management algorithm; thus, only a summary of the DP formulation is presented. The cost function for the global fuel consumption minimization problem is given in Equation (1). Different terms from left penalize the fuel flow rate, the gear shifts, the engine cranking (for start-stop), and the PSS mode, respectively,

$$
\min \left\{\sum_{k=1}^{N}\left(\dot{m}_{f}(k) T_{s}+\alpha\left|n_{g}(k)-n_{g}(k-1)\right|+\beta\left(\max \left(x_{e}(k)-x_{e}(k-1), 0\right)\right)+\lambda\left(1-u_{\mathrm{br}}(k)\right)\right)\right\}
$$

where $k$ refers to the $k$ th step time, $N$ is the problem horizon, which is the full drive cycle, $T_{s}$ is the sampling time equal to $1 \mathrm{~s}, \dot{m}_{f}$ is the fuel flow rate, $n_{g}$ represents the gear number, $x_{e}$ stands for the engine on/off state, and $u_{\mathrm{br}}$ is the PSS brake position used to indicate the PSS mode, where $u_{\mathrm{br}}=0$ is the boosting mode and $u_{\mathrm{br}}=1$ the torque assist mode. The coefficient $\alpha$ controls the gear shift frequency, $\beta$ is the engine cranking fuel penalty, and $\lambda$ has a very small value to enforce the brake locked as the default mode. The full detail of the problem constraints are presented in the original work [15]. The battery state of charge, the engine on/off state, and the gear number are the modeled states. The latter two had to be modeled as states to be penalized in the objective function. The control inputs for this problem are the PSS mode, the commanded torque assist from the electric motor, the engine on/off command, and the gear shift command. A MATLAB-based dynamic programming function [16] was used to solve this problem.

In the prior work the manufacturer map for the electric motor was used to estimate the fuel economy, and no loss was assumed for the planetary gear set and pulleys. However, the experiments showed that both the motor efficiency and its torque limits are different from the manufacturer map. Hence, new experimentally validated maps were produced to update the results in this work. Figure 5 shows the measured efficiency from/to the electric power, measured by an AVL battery emulator, to/from the engine-dynamometer crankshaft, measured using a torque meter. The maximum and minimum motor torque limits are also presented. Compared to the prior maps, the losses were up to $15 \%$ more, especially at low speed and negative torques. The minimum motor torque was also slightly higher at lower engine speeds. Both of these reduced the recuperated power from regenerative braking during a cycle. The DP results presented later in Table 1 are updated with the new map.

Table 1. Drive cycle fuel consumption results for Ford Escape MY2015.

\begin{tabular}{cccccc}
\hline Powertrain & Result Type & Energy Management & FC & $\Delta$ FC & $\Delta$ SoC \\
\hline & & & {$[\mathrm{L} / 100 \mathrm{~km}]$} & {$[\%]$} & {$[\%]$} \\
Turbocharged & Simulation & DP & 6.76 & - & \\
Engine + PSS & Simulation & DP & 5.22 & 22.8 & 0.0 \\
Turbocharged & Experiment & - & 7.29 & - & - \\
Engine + PSS & Experiment & A-ECMS & 5.95 & 18.4 & 1.1 \\
\hline
\end{tabular}




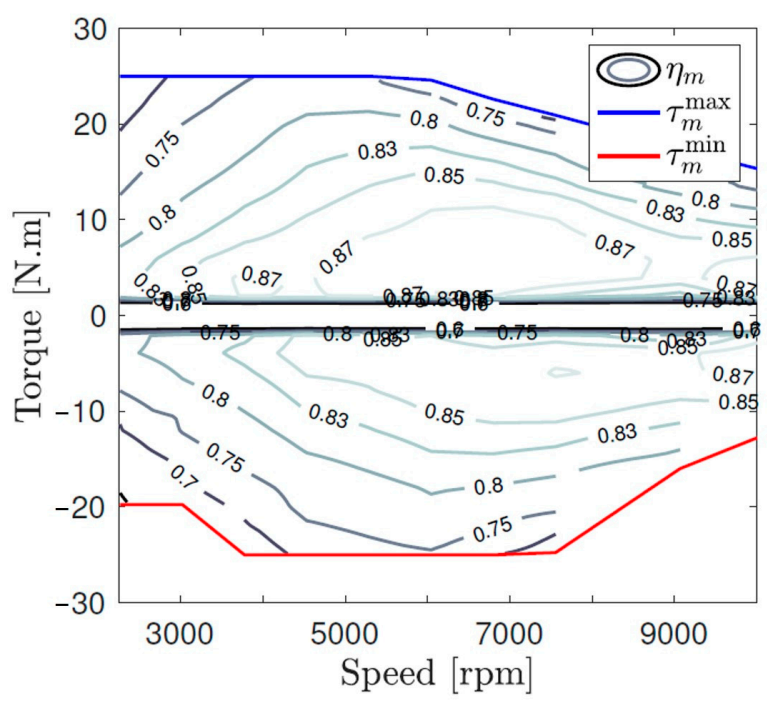

Figure 5. Experimentally generated motor and gear set map.

\subsection{Equivalent Consumption Minimization Strategy}

The equivalent consumption minimization strategy assigns an equivalent fuel flow rate to the electric energy consumption by using an equivalence factor and minimizes the sum of the engine and motor fuel flow rate at only the current time step [8,17]. As this strategy does not need any preview information it can be implemented online. The motor torque, $\tau_{m}$, is calculated as

$$
\tau_{m}=\underset{\tau_{m}}{\operatorname{argmin}}\left(\dot{m}_{f}\left(\tau_{e}, \omega_{e}\right)+\alpha_{\mathrm{eq}} P_{m}\left(\tau_{m}, \omega_{m}\right)\right)
$$

in which $\tau_{e}$ and $\omega_{e}$ represent the engine torque and speed respectively, $\omega_{m}$ is the motor speed, and $\alpha_{\mathrm{eq}}$ is the equivalence factor. The energy management system (EMS) of a vehicle with a PSS has to select the PSS mode first. Only if the torque assist mode is selected will the optimum motor torque need to be determined in the next step to minimize the powertrain fuel consumption. When the boosting mode is selected the motor torque is not an optimization parameter but is instead used to control the boost pressure and, hence, the engine torque.

Boosting is only justified when the requested crankshaft torque, $\tau_{\text {crk }}^{d}$, is larger than the torque limit that the naturally aspirated engine can produce, $\tau_{e, \mathrm{NA}}^{\max }$ (above the blue area in Figure 4), because simultaneous boosting and throttling is not an efficient policy [18]. Therefore, it is fuel efficient to lock and bypass the supercharger when $\tau_{\text {crk }}^{d}<\tau_{e, \mathrm{NA}}^{\max }$. On the other hand, due to the small motor size, the NA engine with direct torque assist from the motor cannot produce a torque higher than $\left(\tau_{e, \mathrm{NA}}+\tau_{\mathrm{TA}}\right)^{\mathrm{max}}$, shown in Figure 4; thus, when a high torque in the yellow area of Figure 4 is requested, the PSS has to work in boosting mode. Finally, when the requested torque is smaller than the maximum powertrain torque in torque assist mode and larger than the NA engine torque limit (green area in Figure 4), the requested torque can be achieved through either mode. A consumption minimization rule is introduced to determine the PSS mode that produces the minimum equivalent fuel consumption as follows:

$$
u_{\mathrm{br}}=\left\{\begin{array}{ccc}
0 & \text { if } & \tau_{\text {crk }}^{d}>\left(\tau_{\mathrm{TA}}+\tau_{e, \mathrm{NA}}\right)^{\max } \\
1 & \text { if } & \tau_{\text {crk }}^{d} \leq \tau_{e, \mathrm{NA}}^{\mathrm{max}} \\
\underset{\substack{\operatorname{argmin} \\
u_{\mathrm{br}}=0,1}}{\left(\dot{m}_{f, \mathrm{eq}}\right)} & \text { otherwise }
\end{array}\right.
$$

in which $u_{\mathrm{br}}$ is the PSS brake position used to represent the PSS mode, and $\dot{m}_{f \text {,eq }}$ is the equivalent fuel flow rate of the engine and motor, computed for each mode as

- $\quad$ Torque assist mode $\left(u_{\mathrm{br}}=1\right)$ : 


$$
\begin{aligned}
\dot{m}_{f, \mathrm{eq}} & =\min _{\tau_{\mathrm{m}}^{d}}\left(\dot{m}_{f}\left(\tau_{e}^{d}, \omega_{e}\right)+\alpha_{\mathrm{eq}} P_{m}\left(\tau_{\mathrm{m}}^{d}, \omega_{m}\right)\right) \\
\tau_{e}^{d} & =\tau_{\mathrm{crk}}^{d}-\tau_{\mathrm{TA}}^{d} \\
\tau_{m}^{d} & =\frac{g_{R}}{n_{\mathrm{im}} n_{\mathrm{ri}}\left(g_{S}+g_{R}\right)} \tau_{\mathrm{TA}}^{d}
\end{aligned}
$$

where the superscript $d$ refers to the desired or commanded values, $g_{R}$ is the ring gear teeth number, $g_{S}$ is the sun gear teeth number, $n_{r i}$ is the ring-to-idler gear ratio, and $n_{\mathrm{im}}$ is the idler-to-motor gear ratio. The variable $\tau_{\mathrm{TA}}$ represents the torque assist from the motor on the crankshaft and is related to the motor torque through (6).

- $\quad$ Boosting mode $\left(u_{\mathrm{br}}=0\right)$ :

$$
\begin{aligned}
\dot{m}_{f, \mathrm{eq}} & =\dot{m}_{f}\left(\tau_{e}^{d}, \omega_{e}\right)+\alpha_{\mathrm{eq}} P_{m}\left(\tau_{e}^{d}, \omega_{e}\right) \\
\tau_{e}^{d} & =\tau_{\mathrm{crk}}^{d}
\end{aligned}
$$

Equation (8) indicates that during boosting mode the entire crankshaft requested torque has to be supplied by the engine. In this mode the supercharger pressure ratio is decoupled from the engine operating speed. Keeping the throttle valve open in the boosted condition reduces the engine losses and increases the efficiency. Adopting this strategy, the steady-state motor power for driving the supercharger can be mapped into engine operating points shown in Figure $2 b$. This map is used to calculate the equivalent fuel flow rate of the motor in boosting mode.

The solution to Equations (2) and (3) is computed for various values of the equivalence factor $\alpha_{\text {eq. }}$. Figure $6 \mathrm{a}-\mathrm{c}$ shows the solution to Equation (3) for equivalence factors of $0.13,0.18$, and $0.23 \mathrm{~kg} / \mathrm{kWh}$, respectively. The green color in these plots indicates boosting mode, while the red color shows torque assist mode. Figure $7 \mathrm{a}-\mathrm{c}$ presents the optimum motor torque during torque assist mode generated from (2) for the same equivalence factors.

The equivalence factor represents the relative value of the electric power. A smaller equivalence factor uses the torque assist mode more often and uses the motor to assist the crankshaft over a larger operating region (more red color in Figures 6a and 7a). A higher equivalence factor increases the penalty for electric power, which causes the ECMS controller to use the boosting mode more often in Figure $6 \mathrm{~b}, \mathrm{c}$ while also using the motor to generate more energy, often at low loads (more green color in Figure $7 b, c)$.

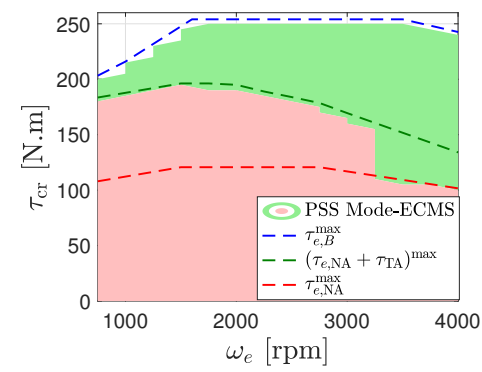

(a) $\alpha_{\mathrm{eq}}=0.13 \mathrm{~kg} / \mathrm{kWh}$.

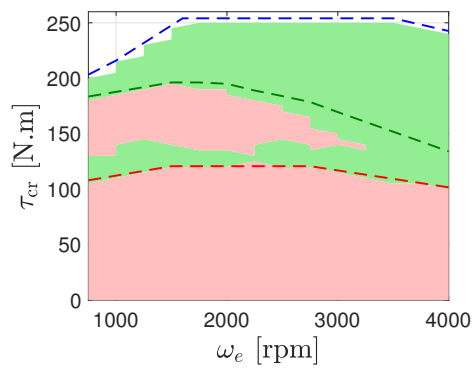

(b) $\alpha_{\mathrm{eq}}=0.18 \mathrm{~kg} / \mathrm{kWh}$.

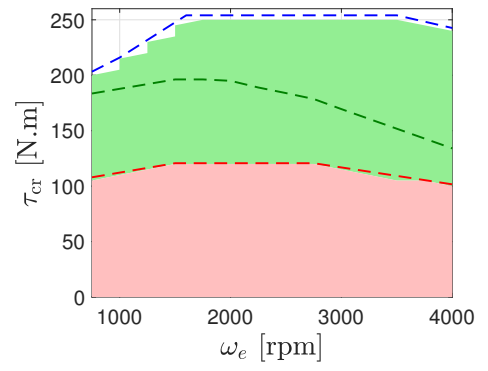

(c) $\alpha_{\mathrm{eq}}=0.23 \mathrm{~kg} / \mathrm{kWh}$.

Figure 6. Equivalent consumption minimization strategy (ECMS)-generated PSS mode for different equivalence factors. The green color represents boosting mode, and the red color indicates torque assist mode. (a) $\alpha_{\text {eq }}=0.13 \mathrm{~kg} / \mathrm{kWh},(\mathbf{b}) \alpha_{\mathrm{eq}}=0.18 \mathrm{~kg} / \mathrm{kWh}$, and (c) $\alpha_{\mathrm{eq}}=0.23 \mathrm{~kg} / \mathrm{kWh}$. Increasing the equivalence factor shifts the optimal strategy from torque assist to favor boosting mode. 


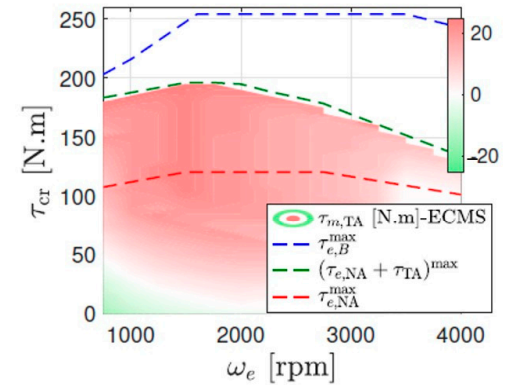

(a) $\alpha_{\mathrm{eq}}=0.13 \mathrm{~kg} / \mathrm{kWh}$.

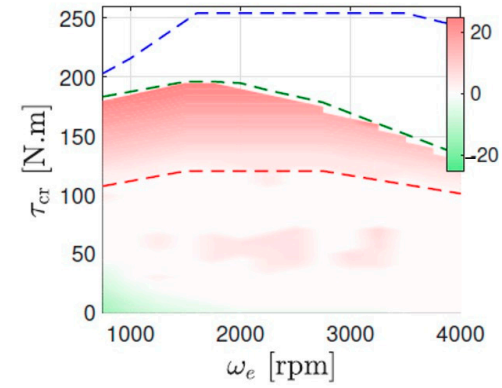

(b) $\alpha_{\text {eq }}=0.18 \mathrm{~kg} / \mathrm{kWh}$

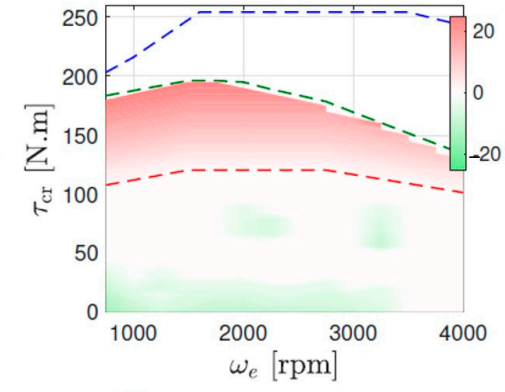

(c) $\alpha_{\mathrm{eq}}=0.23 \mathrm{~kg} / \mathrm{kWh}$

Figure 7. ECMS generated motor torque during torque assist mode for different values of equivalence factor (a) $\alpha_{\text {eq }}=0.13 \mathrm{~kg} / \mathrm{kWh},(\mathbf{b}) \alpha_{\mathrm{eq}}=0.18 \mathrm{~kg} / \mathrm{kWh}$, and (c) $\alpha_{\mathrm{eq}}=0.23 \mathrm{~kg} / \mathrm{kWh}$.

\subsection{Adaptive-ECMS}

The traditional ECMS method requires tuning the equivalence factor offline for every driving profile to ensure that the battery state of charge remains within the desired/operational limit. However, in real-world applications the future velocity profile is not known. Therefore, it is necessary to tune the ECMS factor in real time to ensure acceptable operation of the energy management system, especially when starting from an unfavorable initial condition. A-ECMS adjusts the equivalence factor based on drive cycle prediction, driving pattern recognition, or feedback from the battery state of charge [19]. In this work a modification of the approach that uses the SoC feedback [20] is adopted. The equivalence factor is adjusted as

$$
\alpha_{\mathrm{eq}}(k)= \begin{cases}0.25 & \text { if } \quad \text { oo }<40 \% \\ 0.10 & \text { if } \quad \text { oC }>60 \% \\ \max \left(\min \left(\alpha_{\mathrm{eq}}(k-1)+q(S o C(k)-S o C(k-1)), 0.25\right), 0.10\right) & \text { otherwise }\end{cases}
$$

where $q$ is a constant coefficient. The suitable sampling time for Equation (9) depends on the relative size of the energy storage and energy consumption. Simulations showed that a sampling time of less than $1 \mathrm{~min}$ can keep the SoC in 40-60\% range for the tested drive cycle. However, a sampling time of $15 \mathrm{~s}$ was selected for the experiments for a tighter control over SoC, without adding a significant computational effort. Further investigations into sampling time dependence on drive cycle and vehicle parameters are left for future development. Figure 8 shows the A-ECMS implementation for hardware-in-the-loop experiments presented in the next section. $P_{b}$ represents the battery power.

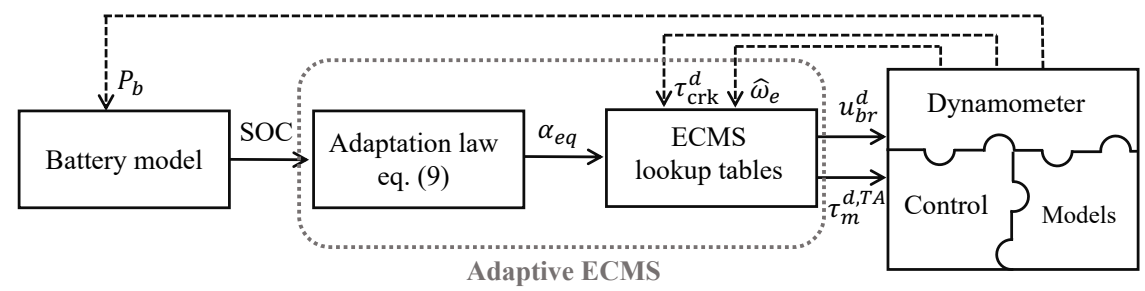

Figure 8. A-ECMS implementation for hardware-in-the-loop experiments.

\section{Experimental Setup}

\subsection{Testbed}

Figure 9 shows a picture of the engine-dynamometer experimental testbed, which includes an AVL AC transient dynamometer, an instrumented 1.6 L Ford EcoBoost engine, and the power split supercharger by EATON. An AVL SESAM-FTIR emission measurement bench is used to measure 
exhaust gas species and calculate fuel flow rate along with a hot wire air flow rate meter. An AVL battery simulator is used to power the PSS and measure the motor current and voltage. A rapid prototyping electronic control system (RPECS ${ }^{\mathrm{TM}}$ ) from Southwest Research Institute (SwRI) was used to integrate all engine controllers, the online energy management system, and implement real-time vehicle and driver models.

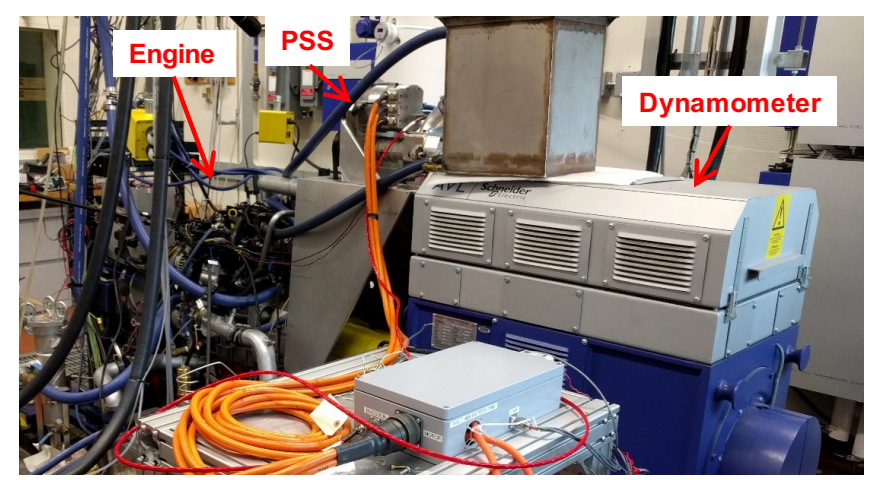

Figure 9. Engine-dynamometer experimental testbed.

\subsection{Implementing A-ECMS and Hardware-in-the-Loop Experiments}

In the hardware-in-the-loop experiments the engine and the PSS are the physical hardware, and the vehicle, the driver, and the battery are models coded in RPECS ${ }^{\mathrm{TM}}$. The AC dynamometer is programmed to play the role of the vehicle body and follow a drive cycle speed profile. In these experiments the driver model issues an accelerator or brake pedal based on the vehicle velocity tracking error. From this command the energy management system and the low-level controllers compute the actuator positions for the engine, dynamometer, and the PSS, including the throttle position $\left(u_{\theta}^{d}\right)$, motor torque $\left(\tau_{m}^{d}\right)$, the PSS brake command $\left(u_{\mathrm{br}}^{d}\right)$, the supercharger bypass command $\left(u_{\mathrm{bp}}^{d}\right)$, and the engine speed $\left(\omega_{e}^{d}\right)$. The produced crankshaft torque $\left(\hat{\tau}_{\text {crk }}\right)$ is measured and fed back into the vehicle longitudinal dynamics to calculate the next vehicle speed. This feedback system, presented also in Figure 10, permits velocity tracking and an accurate drive cycle fuel economy measurement. Note that the AC dynamometer can track either a desired speed or a desired torque profile. The torque tracking mode is not always safe because, in this case, the crankshaft speed is determined by the torque balance between the engine and the dynamometer. Operating in this mode in case of a subsystem failure, communication delay, or software bug can result in over speeding the engine, damage, or complete destruction. Therefore, in this work the dynamometer was always used in the speed control mode, and as shown later in the experimental results, the dynamometer controller did an impeccable job in tracking the engine speed set point. The following sections present HIL implementation for the two propulsion modes, locked and unlocked torque converter. All models and the energy management system are implemented in a 5 ms loop in RPECS ${ }^{\mathrm{TM}}$.

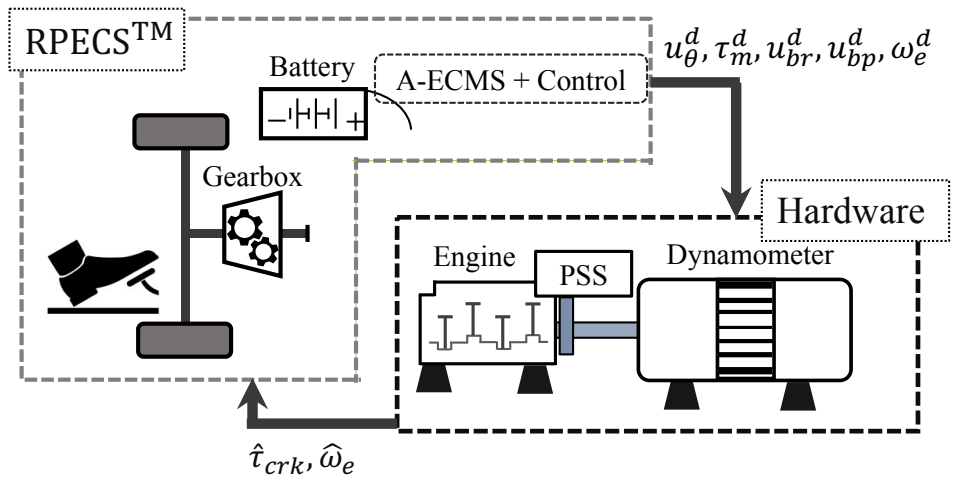

Figure 10. Hardware-in-the-loop (HIL) implementation. 


\subsubsection{Hardware-in-the-Loop Implementation for Locked Torque Converter}

When the torque converter (TC) is locked, the vehicle speed is computed from the longitudinal vehicle dynamics and the measured crankshaft torque as follows:

$$
\begin{aligned}
M \frac{d}{d t} v & =F_{t}-F_{b}-F_{l} \\
F_{t} & =\frac{1}{R_{w}}\left(i_{g} \hat{\tau}_{\mathrm{crk}}-\tau_{\text {loss }}\right) \\
\omega_{e}^{d} & =\frac{v}{i_{g} R_{w}}
\end{aligned}
$$

where $M$ is the vehicle mass, $v$ is the vehicle velocity, $F_{t}$ is the traction force, $F_{b}$ is the braking force, $F_{l}$ is the road load, $i_{g}$ is the gear ratio, $\tau_{\text {loss }}$ is torque loss in the transmission, $R_{w}$ is the wheel radius, and $\omega_{e}^{d}$ is the engine speed computed from the vehicle speed and fed back into the dynamometer. The details of the vehicle and transmission models are presented elsewhere [14].

The requested tractive torque, $\tau_{\mathrm{trc}}^{d}$, when the accelerator pedal is active is linearly mapped to the pedal position, $u_{\text {acc }}$ :

$$
\tau_{\text {trc }}^{d}=u_{\mathrm{acc}}\left(\tau_{e, \mathrm{~B}}^{\max }-\tau_{e}^{\min }\right)+\tau_{e}^{\min }
$$

where $\tau_{e}^{\min }$ is the minimum engine torque, and $\tau_{e, \mathrm{~B}}^{\max }$ is from Figure 4 . The requested braking torque on the gearbox inlet shaft, $\tau_{\mathrm{brk}}^{d}$, is computed from the brake pedal position, $u_{\mathrm{brk}}$ produced by the driver model:

$$
\tau_{\mathrm{brk}}^{d}=\frac{u_{\mathrm{brk}} \tau_{\mathrm{brk}}^{\max }}{i_{\mathrm{g}}}
$$

where $\tau_{\mathrm{brk}}^{\max }$ is the maximum braking torque on the wheels.

The PSS optimal mode, $u_{\mathrm{br}}^{d}$, during traction (which is $\tau_{\mathrm{crk}}^{d}>0$ ) and the optimum motor torque in torque assist mode, $\tau_{m}^{d, \mathrm{TA}}$, are computed offline and stored in look up tables based on the requested crank torque, the measured engine speed, and the equivalence factor:

$$
\begin{aligned}
u_{\mathrm{br}}^{d} & =\Gamma\left(\tau_{\mathrm{crk}}^{d}, \hat{\omega}_{e}, \alpha_{\mathrm{eq}}\right) \\
\tau_{m}^{d, \mathrm{TA}} & =\Lambda\left(\tau_{\mathrm{crk}}^{d}, \hat{\omega}_{e}, \alpha_{\mathrm{eq}}\right)
\end{aligned}
$$

The desired engine torque is

$$
\tau_{e}^{d}=\left\{\begin{array}{lll}
\tau_{\mathrm{crk}}^{d} & \text { if } & u_{\mathrm{br}}^{d}=0 \\
\tau_{\mathrm{crk}}^{d}-\tau_{m}^{d, \mathrm{TA}} \frac{\left(g_{R}+g_{S}\right) n_{\mathrm{im}} n_{\mathrm{ri}}}{g_{R}} & \text { if } & u_{\mathrm{br}}^{d}=1 .
\end{array}\right.
$$

Finally, the desired intake manifold pressure is computed from the engine speed and the desired engine torque:

$$
p_{\mathrm{im}}^{d}=\Xi\left(\tau_{e}^{d}, \omega_{e}\right) .
$$

When the desired manifold pressure is less than the ambient pressure the supercharger is bypassed $\left(u_{\mathrm{bp}}^{d}=1\right)$ and the intake throttle is used to control the intake manifold pressure, while when the desired intake manifold pressure is higher than the ambient pressure the throttle is wide open and the supercharger speed is controlled by the motor to achieve the desired intake manifold pressure. Both the throttle controller and the supercharger speed controller are feedforward PI controllers. The supercharger speed controller has an inner PI controller to manipulate the motor torque to achieve the desired supercharger speed. The details of the low-level controllers are presented elsewhere [14]. 
The motor torque during regenerative braking, $\tau_{m}^{d, \text { Reg }}$, is computed by

$$
\tau_{m}^{d, \operatorname{Reg}}=\max \left(\tau_{c r k}^{d} \frac{g_{R}}{\left(g_{R}+g_{S}\right) n_{\mathrm{im}} n_{\mathrm{ri}}}, \tau_{m}^{\min }\right)
$$

where $\tau_{m}^{\min }$ is the minimum motor torque shown in Figure 5. The PSS mode is set to torque assist mode during braking. Note that Equation (19) is the solution to Optimization (2) since simultaneous generation from the engine and regenerative braking is prohibited in here $\left(\tau_{e}=\tau_{e}^{\text {min }}\right.$ during braking). Finally, the commanded motor torque, $\tau_{m}^{d}$, comes from either the PI controller $\left(\tau_{m}^{d, \mathrm{PI}}\right)$, regenerative braking, or the torque assist (from A-ECMS) depending the PSS mode and the requested tractive torque sign:

$$
\tau_{m}^{d}=\left\{\begin{array}{llc}
\tau_{m}^{d, \mathrm{PI}} & \text { if } & u_{\mathrm{br}}^{d}=0 \\
\tau_{m}^{d, \mathrm{TA}} & \text { if } & u_{\mathrm{br}}^{d}=1, \tau_{\text {trc }}^{d} \geq 0 \\
\tau_{m}^{d, \mathrm{Gen}} & \text { if } & u_{\mathrm{br}}^{d}=1, \tau_{\text {trc }}^{d}<0
\end{array}\right.
$$

\subsubsection{Hardware-in-the-Loop Implementation for Unlocked Torque Converter}

When the torque converter is unlocked, there is no mechanical coupling between the engine and the wheels. However, in order to use the dynamometer in the speed control mode with an unlocked torque converter, it is assumed that the engine speed is equal to its idling speed when the TC unlocks $\left(\omega_{e}^{d}=\omega_{e, \text { idle }}\right)$. The minimum engine torque to hold the idle speed is calculated from the torque converter $\mathrm{K}$-factor $(K)$ and torque ratio (TR), which are functions of turbine to pump speed ratio (SR):

$$
\begin{aligned}
\mathrm{SR} & =\frac{\omega_{\mathrm{tct}}}{\omega_{\mathrm{tcp}}} \\
\tau_{\mathrm{tcp}} & =\left(\frac{\omega_{\mathrm{tcp}}}{K}\right)^{2} \\
\tau_{\mathrm{tct}} & =\tau_{\text {tcp }} \times \mathrm{TR}
\end{aligned}
$$

where $\omega_{\text {tct }}$ is the torque converter turbine speed, $\tau_{\text {tct }}$ is the turbine torque, $\tau_{\text {tcp }}$ is the pump torque, and $\omega_{\text {tcp }}$ is the pump speed. Given that $\omega_{\text {tcp }}$ is equal to the engine idling speed when the torque converter unlocks, the minimum torque on the crankshaft when the turbine speed drops to less than engine idling speed can be computed as a function of turbine speed, $\tau_{\mathrm{tcp}}^{*}\left(\omega_{\mathrm{tct}}\right)$. Accordingly, the minimum torque on the crankshaft, $\tau_{\mathrm{crk}}^{\min }$, is computed by

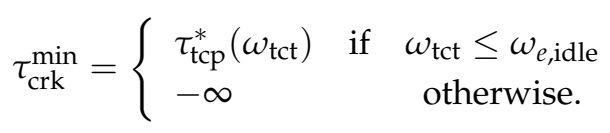

The requested torque on the crankshaft is

$$
\tau_{\mathrm{crk}}^{d}=\max \left(\tau_{\mathrm{trc}}^{d}, \tau_{\mathrm{brk}}^{d}, \tau_{\mathrm{crk}}^{\min }\right) .
$$

Equation (25) imposes some positive torque demand on the crankshaft at low vehicle speed to maintain the engine idling speed, and it disables regenerative braking under these conditions. Similar to the locked torque converter case, Equations (15)-(18) and (20) are used to determine $u_{\theta}^{d}$, $\tau_{m}^{d}, u_{\mathrm{bp}}^{d}$, and $u_{\mathrm{br}}^{d}$ in this mode. The engine speed is set equal to the idling speed, $\omega_{e}^{d}=\omega_{e, \text { idle, }}$ and (11) has to be corrected to include the torque converter torque ratio,

$$
F_{t}=\frac{1}{R_{w}}\left(i_{g} \hat{\tau}_{\text {crk }} \times \mathrm{TR}-\tau_{\text {loss }}\right) .
$$




\subsubsection{Engine Start-Stop}

In a vehicle the engine is connected to the transmission, and the transmission clutch is open during engine starts. On the engine dynamometer the engine is permanently connected to the dynamometer with a large inertia. Therefore, it is not possible to mimic the engine start-stops with a dynamometer. To emulate the start-stop behavior, the stopped portions of the drive cycle, where the engine is turned off, are removed from the velocity profile for the vehicle with the PSS, and a fuel penalty is added for each start-stop event. The next section shows the resulted velocity profiles in addition to other experimental results.

\section{Experimental Results}

Figure 11 shows the velocity tracking for FTP75 drive cycle from the HIL experiments for the baseline turbocharged engine and the engine when the PSS replaces the turbocharger. In addition to the vehicle speed and reference speed, $v^{\text {ref }}$, the standard minimum velocity threshold , $v^{\text {min }}$, is also plotted, showing that both engines successfully follow the cycle profile. The following sections document the fuel consumption and PSS operation details during the HIL experiments.

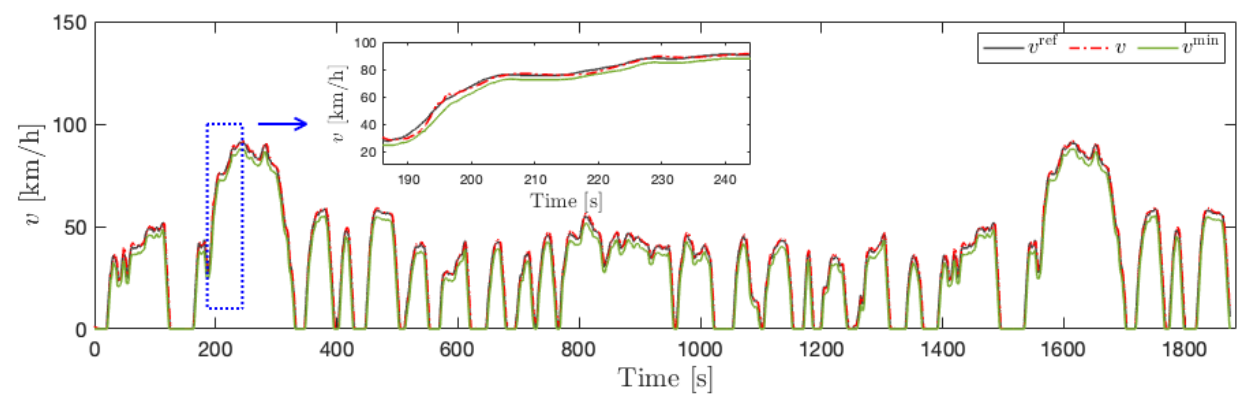

(a) Turbocharged baseline.

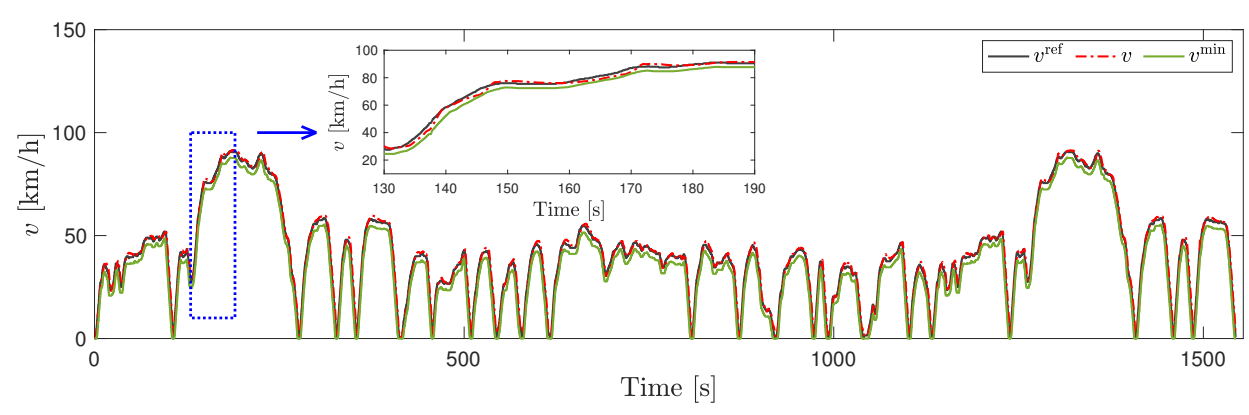

(b) Engine with PSS.

Figure 11. Velocity tracking during hardware-in-the-loop experiments, (a) vehicle with turbocharged engine, (b) vehicle with the PSS, stopped portions of the cycle removed to emulate start-stop.

\subsection{Fuel Consumption Reduction with PSS}

Table 1 summarizes the experimental fuel consumption (FC) results along with the predicted global minimum fuel consumption, produced with DP and a simplified vehicle model. The gearshifts of the baseline turbocharged engine are also optimized by DP in results shown in the first row of Table 1. The same gearshift strategy is used for the turbocharged engine and the engine with PSS during experiments. DP predicts that the engine with the PSS consumes $22.8 \%$ less fuel compared to the turbocharged engine. The HIL experiments were repeated three times for the PSS and two times for the baseline turbocharged engine, and the mean FC values are reported in the table. The FC values varied from 5.92 to $5.991 / 100 \mathrm{~km}$ for the engine with PSS and from 7.20 to $7.37 \mathrm{l} / 100 \mathrm{~km}$ for the turbocharged engine. The HIL experiments show that the engine with the PSS consumed $18.4 \%$ less fuel compared to the baseline turbocharged engine on average, which is only $4.4 \%$ higher 
than the global minimum FC from DP. This result substantiates the effectiveness of the implemented energy management system considering that A-ECMS does not use any preview information and only minimizes its cost function at a current time step. There is some offset between the absolute values of FC in simulations versus experiments. The reason is that the simulations use a fuel consumption map produced by GT-Power simulations, which is shown to accurately predict the fuel consumption variation with load and speed and between different engine configurations, but has a constant offset compared to the experimentally measured fuel consumption [14].

Figure 12a shows the battery state of charge $(\mathrm{SoC})$ variation during the HIL experiment. Starting from $50 \%$ SoC, the battery SoC maintained between $44 \%$ to $51 \%$ during the experiment, showing the possibility of further battery size and system cost reduction. Figure $12 \mathrm{~b}$ shows the equivalence factor. The adaptation rule (9) can keep the SoC between $40 \%$ and $60 \%$, but still the initial value of $\alpha_{\text {eq }}(0)$ was tuned to get a final SoC value close to $50 \%$. Finally, the fuel mass was corrected as follows to account for the small $\Delta \mathrm{SoC}$ between the start and end of the cycle,

$$
W_{f}^{\text {cor }}=W_{f}+U C_{n} \bar{\alpha}_{\mathrm{eq}} \Delta S o C
$$

where $W_{f}$ is the fuel mass, $W_{f}^{\text {cor }}$ is the corrected fuel mass, $U$ is the battery open circuit voltage, $C_{n}$ is the battery capacity, and $\bar{\alpha}_{\text {eff }}$ is the average equivalence factor during the experiment from Figure $12 \mathrm{~b}$.

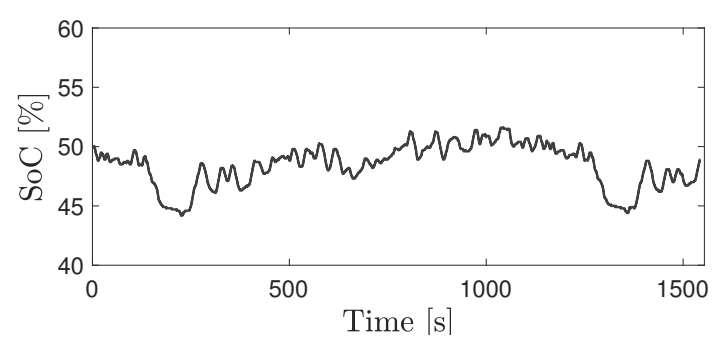

(a) Battery state of charge.

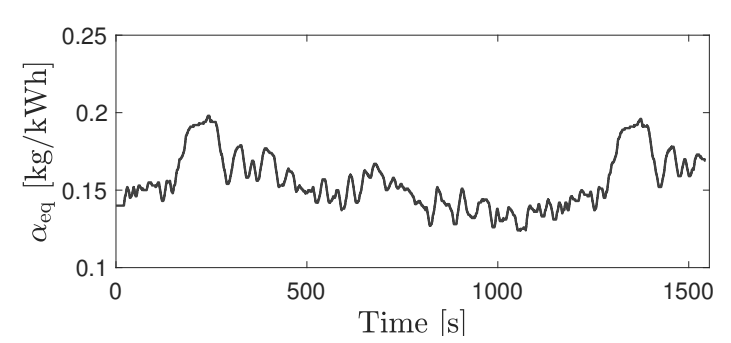

(b) Equivalence factor.

Figure 12. The battery state of charge and A-ECMS equivalence factor variation during experiments,

(a) state of charge, (b) equivalence factor.

\subsection{Power Split Supercharger Operation during a Transient Drive Cycle}

This section presents the details of the hardware and energy management system operation during the HIL experiments. Figure 13 shows the intake manifold pressure, $p_{\mathrm{im}}$. Figure 13a shows $p_{\mathrm{im}}$ over the entire cycle along with the PSS brake position. The intake manifold pressure increased to more than the ambient pressure (around $100 \mathrm{kpa}$ ) only during few instances, which correspond to vehicle accelerations where the PSS switches to boosting mode $\left(u_{\mathrm{br}}=0\right)$. Figure $13 \mathrm{~b}$ shows $p_{i m}$ variation during a portion of the cycle in more detail (marked with blue square in Figures 11b and 13a) on top of the desired signal value, $p_{\mathrm{im}}^{\mathrm{des}}$, and the supercharger bypass valve position. As mentioned before, when $p_{\mathrm{im}}^{\text {des }}$ is less than the ambient pressure, the supercharger is bypassed and the throttle controls $p_{\mathrm{im}}$. When $p_{\mathrm{im}}^{\mathrm{des}}$ increases to more than the ambient pressure, the throttle opens wide, the bypass valve closes, and the supercharger controls $p_{\mathrm{im}}$. With the current controller gains, the $0 \rightarrow 90 \%$ response time to achieve full boost is around $1 \mathrm{~s}$, but it can be reduced to around $0.7 \mathrm{~s}$ with more rigorous calibration and gain scheduling.

Figure 14 shows the engine speed, the motor speed, and the supercharger brake position for the same portion of drive cycle. The motor speed is multiplied by $\frac{R}{n_{\mathrm{im}} n_{\mathrm{ri}}\left(g_{R}+g_{S}\right)}$, which corresponds to the gear ratio between the motor and crankshaft when the supercharger is locked. During the boosting mode the supercharger speed, $\omega_{\mathrm{sc}}$, is related to the motor and crankshaft speed by

$$
\omega_{e}=\frac{g_{S}}{\left(g_{S}+g_{R}\right)} \omega_{\mathrm{sc}}+\frac{R}{n_{\mathrm{im}} n_{\mathrm{ri}}\left(g_{R}+g_{S}\right)} \omega_{m}
$$


when the PSS switches to boosting mode the brake opens and the motor has to decrease its own speed by applying some negative torque to increase the supercharger speed. The motor torque and power during the selected interval are shown in Figure 15. The motor torque is the reported value by the motor control unit, and the motor power, $P_{m}$, is measured by the AVL battery simulator. The time gap corresponds to a vehicle acceleration; hence, the motor is assisting the crankshaft when PSS is in torque assist mode (positive motor torque). When switching to boosting mode the motor initially applies some negative torque to speed up the supercharger, and then the motor torque is controlled to track the desired intake manifold pressure. Finally, when boosting is not required, the motor speed increases by applying a positive torque, and when the motor speed is high enough (supercharger speed close to zero) the supercharger is locked again. The brake position is also shown on these plots to distinguish between boosting and torque assist modes. Note that the motor power sign depends on both its torque and speed signs because the PSS motor can rotate in both directions.

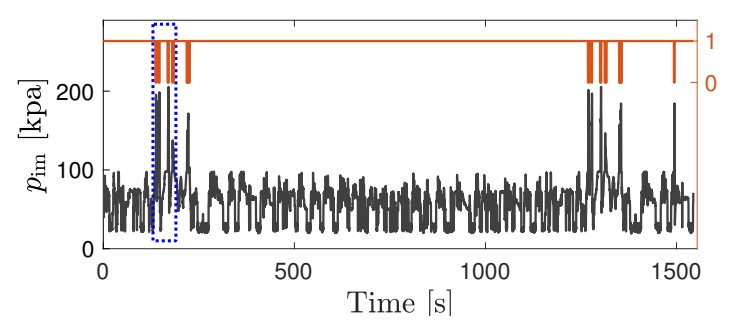

(a) Intake manifold pressure during the entire cycle.

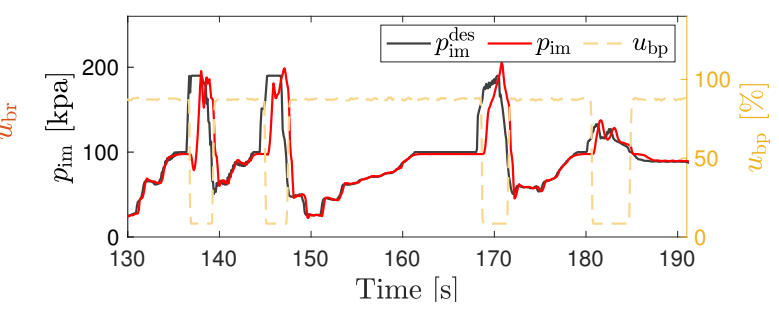

(b) Intake manifold pressure during selected acceleration.

Figure 13. Intake manifold pressure during FTP75 cycle, (a) intake manifold pressure and PSS mode over the entire cycle, (b) intake manifold pressure, desired intake manifold pressure, and supercharger bypass during $t=130 \mathrm{~s}$ to $t=190 \mathrm{~s}$.

The final piece of the HIL experiments is controlling the desired engine speed. Figure 16 shows the commanded engine speed and its actual value controlled by the dynamometer. As seen, the dynamometer can perfectly track the desired engine speed.

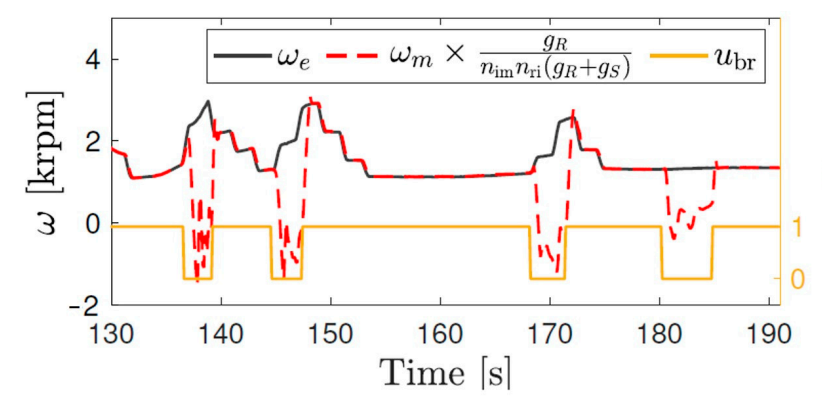

Figure 14. Engine and motor speed for the hardware-in-the-loop experiments during $t=130 \mathrm{~s}$ to $t=190 \mathrm{~s}$.
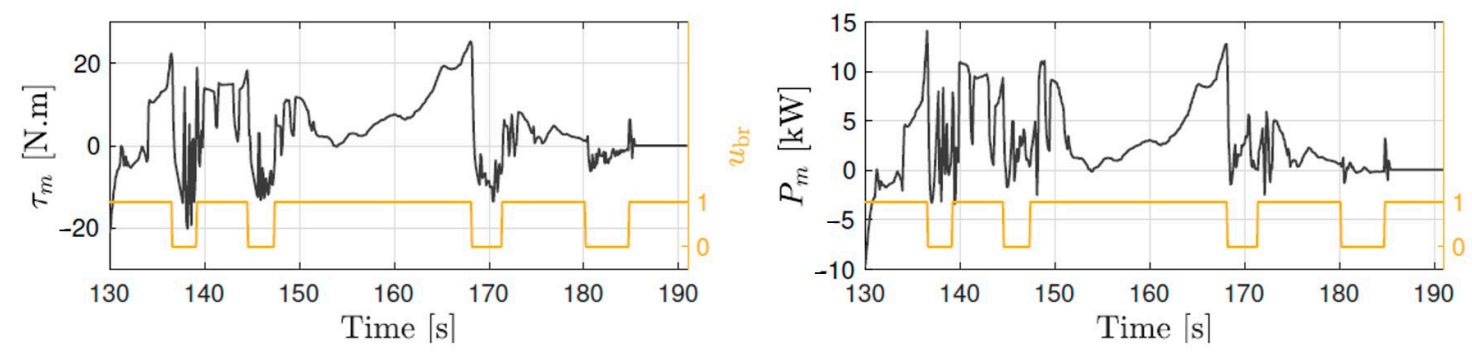

(a) Motor torque

Figure 15. Motor operation for the hardware-in-the-loop experiments during $t=130 \mathrm{~s}$ to $t=190 \mathrm{~s}$ (a) motor torque, (b) motor power. 


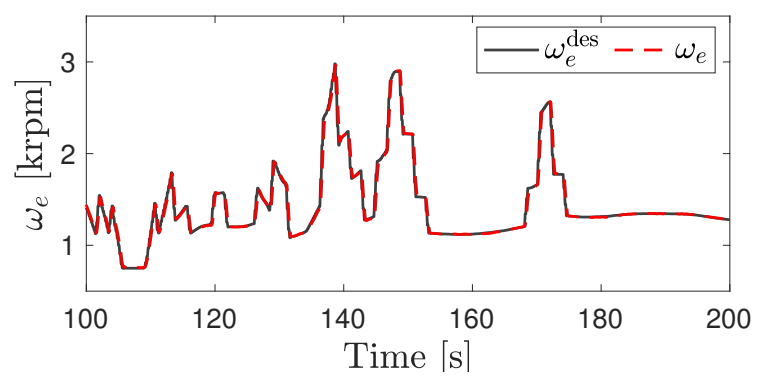

Figure 16. Engine speed and its desired value for the hardware-in-the-loop experiments during $t=130 \mathrm{~s}$ to $t=190 \mathrm{~s}$.

\section{Conclusions}

This work presented optimal energy management and hardware-in-the loop experiments for a novel low-voltage hybrid system that can be used either as a flexible supercharger or as a parallel hybrid system, enabling start-stop, regenerative braking, and torque assist. An adaptive equivalent consumption minimization strategy from the literature was modified and customized to the PSS system for selecting both the device mode and the power split ratio in hybrid mode. It was shown that when the relative cost of the electric power is higher, the algorithm chooses to use the supercharger across a wider range of operating points, while when the electric power is relatively cheaper the energy management system supplies the motor torque directly to the engine crankshaft. The implementation of drive cycle hardware-in-the loop experiments on an engine dynamometer testbed was discussed in detail, and some of practical aspects were explained. It was shown that the new device with the developed energy management system decreased Ford Escape fuel consumption by $18.4 \%$ compared to a baseline turbocharged engine over the FTP75 standard cycle, which is only $4.4 \%$ less than the global optimal solution from dynamic programming. Finally, the details of the PSS operation and mode transitions during experiments were shown and discussed in detail. Possible future research directions would be further analysis of the A-ECMS adaptation law and testing the PSS and the developed A-ECMS algorithm in a vehicle.

Author Contributions: Conceptualization, S.N., J.S., R.M. and A.S.; methodology, S.N.; software, S.N. and R.M.; validation, S.N., J.S. and R.M.; formal analysis, S.N.; writing-original draft preparation, S.N.; writing-review and editing, R.M. and A.S.; supervision, A.S.; project administration, A.S.; funding acquisition, A.S. and J.S. All authors have read and agreed to the published version of the manuscript.

Funding: The information, data, or work presented herein was funded in part by the Advanced Research Projects Agency-Energy (ARPA-E), U.S. Department of Energy, under Award Number DE-AR0000659. The views and opinions of authors expressed herein do not necessarily state or reflect those of the United States Government or any agency thereof.

Acknowledgments: The authors would like to thank the EATON corporation and Southwest Research Institute for providing technical support instrumental to the success of this work.

Conflicts of Interest: The authors declare no conflict of interest. The funders had no role in the design of the study; in the collection, analyses, or interpretation of data; in the writing of the manuscript, or in the decision to publish the results.

\section{Abbreviations}

The following abbreviations are used in this manuscript:

A-ECMS adaptive equivalent consumption minimization strategy

DP dynamic programming

ECMS equivalent consumption minimization strategy

EMS energy management system

eSC electric supercharger

FC fuel consumption

HEV hybrid electric vehicle 


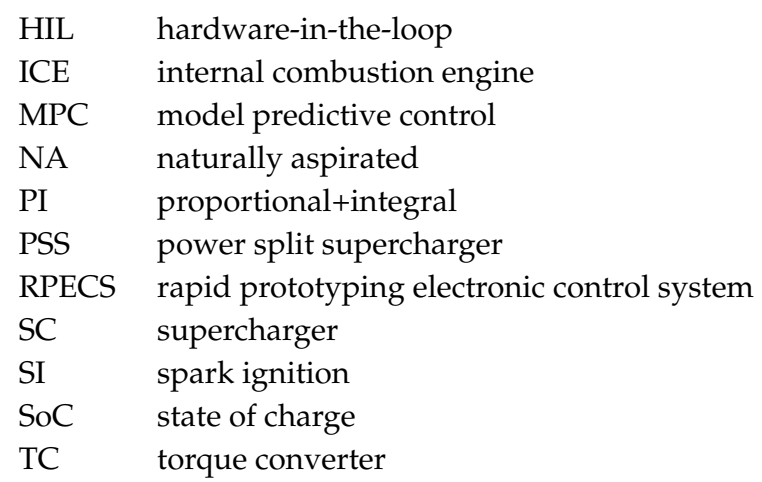

\section{References}

1. Ehsani, M.; Gao, Y.; Miller, J.M. Hybrid electric vehicles: Architecture and motor drives. Proc. IEEE 2007, 95, 719-728. [CrossRef]

2. Bureau of Transportation Statistics. Available online: https://www.bts.gov/content/gasoline-hybrid-andelectric-vehicle-sales (accessed on 31 March 2020).

3. King, J.; Heaney, M.; Saward, J.; Fraser, A.; Criddle, M.; Cheng, T.; Morris, G.; Bloore, P. HyBoost: An Intelligently Electrified Optimised Downsized Gasoline Engine Concept. In Proceedings of the FISITA 2012 World Automotive Congress; Springer: Berlin/Heidelberg, Germany, 2013; pp. 483-496.

4. Volvo. Available online: https://www.volvocars.com (accessed on 1 March 2020).

5. Panday, A.; Bansal, H.O. A review of optimal energy management strategies for hybrid electric vehicle. Int. J. Veh. Technol. 2014. [CrossRef]

6. Enang, W.; Bannister, C. Modelling and control of hybrid electric vehicles (A comprehensive review). Renew. Sustain. Energy Rev. 2017, 74, 1210-1239. [CrossRef]

7. Gao, J.; Sun, F.; He, H.; Zhu, G.G.; Strangas, E.G. A comparative study of supervisory control strategies for a series hybrid electric vehicle. In Proceedings of the 2009 Asia-Pacific Power and Energy Engineering Conference, Wuhan, China, 27-31 March 2009; pp. 1-7.

8. Paganelli, G.; Delprat, S.; Guerra, T.M.; Rimaux, J.; Santin, J.J. Equivalent consumption minimization strategy for parallel hybrid powertrains. In Proceedings of the Vehicular Technology Conference, IEEE 55th Vehicular Technology Conference, VTC Spring 2002, Birmingham, AL, USA, 6-9 May 2002; Volume 4, pp. 2076-2081.

9. Borhan, H.; Vahidi, A.; Phillips, A.M.; Kuang, M.L.; Kolmanovsky, I.V.; Di Cairano, S. MPC-based energy management of a power-split hybrid electric vehicle. IEEE Trans. Control. Syst. Technol. 2012, 20, 593-603. [CrossRef]

10. Lin, C.C.; Peng, H.; Grizzle, J. A stochastic control strategy for hybrid electric vehicles. In Proceedings of the American Control Conference, Boston, MA, USA, 30 June-2 July 2004; Volume 5, pp. 4710-4715.

11. Lin, C.C.; Peng, H.; Grizzle, J.W.; Kang, J.M. Power management strategy for a parallel hybrid electric truck. IEEE Trans. Control. Syst. Technol. 2003, 11, 839-849.

12. Nazari, S.; Siegel, J.B.; Stefanopoulou, A. Optimal Energy Management for a Mild Hybrid Vehicle with Electric and Hybrid Engine Boosting Systems. IEEE Trans. Veh. Technol. 2019, 68, 3386-3399 [CrossRef]

13. Nazari, S.; Middleton, R.; Siegel, J.; Stefanopoulou, A. Equivalent Consumption Minimization Strategy for a Power Split Supercharger; No. 2019-01-1207; SAE Technical: Detroit, MI, USA, 2019.

14. Nazari, S.; Middleton, R.; Sugimori, K.; Siegel, J.; Stefanopoulou, A. Assessing a hybrid supercharged engine for diluted combustion using a dynamic drive cycle simulation. SAE Int. J. Altern. Powertrains 2018, 7, 351-368. [CrossRef]

15. Nazari, S.; Siegel, J.; Stefanopoulou, A. Optimal energy management for a hybrid electric vehicle with a power split supercharger. In Proceedings of the 2018 IEEE Vehicle Power and Propulsion Conference (VPPC), Chicago, IL, USA, 27-30 August 2018; pp. 1-6.

16. Sundstrom, O.; Guzzella, L. A generic dynamic programming Matlab function. In Proceedings of the Control Applications, (CCA) \& Intelligent Control, (ISIC), St. Petersburg, Russia, 8-10 July 2009; pp. 1625-1630. 
17. Paganelli, G.; Tateno, M.; Brahma, A.; Rizzoni, G.; Guezennec, Y. Control development for a hybrid-electric sport-utility vehicle: strategy, implementation and field test results. In Proceedings of the American Control Conference, Arlington, VA, USA, 25-27 June 2001; Volume 6, pp. 5064-5069.

18. Nazari, S.; Stefanopoulou, A.; Martz, J. Minimum backpressure wastegate control for a boosted gasoline engine with low pressure external EGR. In Proceedings of the ASME 2016 Dynamic Systems and Control Conference, American Society of Mechanical Engineers, Ann Arbor, MI, USA, 12-16 October 2016; p. V002T20A002.

19. Onori, S.; Serrao, L. On Adaptive-ECMS strategies for hybrid electric vehicles. In Proceedings of the international scientific conference on hybrid and electric vehicles, Malmaison, France, 6-7 December 2011; Volume 67.

20. Sun, C.; Sun, F.; He, H. Investigating adaptive-ECMS with velocity forecast ability for hybrid electric vehicles. Appl. Energy 2017, 185, 1644-1653. [CrossRef]

Publisher's Note: MDPI stays neutral with regard to jurisdictional claims in published maps and institutional affiliations.

(C) 2020 by the authors. Licensee MDPI, Basel, Switzerland. This article is an open access article distributed under the terms and conditions of the Creative Commons Attribution (CC BY) license (http://creativecommons.org/licenses/by/4.0/). 